\title{
Analysis on the Landscape Design in the Ecological Planning Concept ZHOU Xu-dan ${ }^{1, a}$,Qi Yue ${ }^{2, b}$, QI Hao ${ }^{3, c}$, \\ ${ }^{1}$ College of Horticulture, Jilin Agricultural University,130118 China \\ ${ }^{2}$ College of Literature,Changchun University of Science and Technology,130022 China \\ ${ }^{3}$ School of Art \& Design,JiLin JianZhun University,130118 China

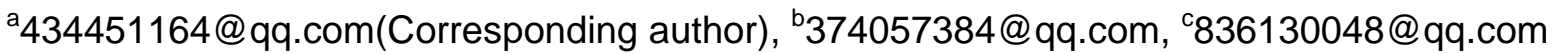

Key words: Ecological planning; Landscape; Design

\begin{abstract}
The ecological garden is the inheritance and development of traditional garden experience; follow the principle of ecology, the construction of multi-level and multiple structures, multi-function plant community of science. To establish new order of the associated humans, animals, plants and ecological beauty is scientific beauty and cultural beauty and artistic beauty. Guided by the economics, emphasizing the direct economic benefits, are indirect economic benefits. Application system engineering development garden, hand in hand with the development of ecological, social and economic benefits, realize the virtuous circle, for human to create clean and beautiful, the ecological environment of civilization. Its core is to use ecology principles guiding the construction of garden plant landscape, and truly achieve the sustainable development of city landscape construction ideal goal.
\end{abstract}

\section{Introduction}

Landscape is people in the city to be close to nature, enjoy the outdoor life place, which is in its ecosystem, human in a position of the designers, users and administrators. Design elements including landscape terrain, buildings, plants and water, has a great deal of artificial ingredients, maintain its normal operation of energy and material from the external landscape ecological system, so it has a lot of openness and instability. Both artificial building gardens, and nature of our natural wealth, can be regarded as a kind of life, can use the power of nature is self control, self adjusting and self circulation. In recent years, the human in landscape architecture planning and design are increasingly considering the ecological characteristics of landscape architecture. From the ecological point of view, landscape design should try to improve people's living environment, to compensate the urban ecological negative effects as far as possible. The ultimate goal of landscape ecological principles in the design of application for: coordinated with good ecological process, the damage to the environment affect the minimum and maximum output.

\section{The ecological design concept}

"Design" is a person of a particular purpose or need into a specific physical form or expression of the process. It is human conscious shaping material, energy and process to meet desired needs and desires heart. Malaysia's famous architect Yang scripture think: "ecological design is by design to obtain an overall comprehensive consideration, it is included in a design system in the whole process of life cycle, prudent use of energy and materials, and through the design to reduce the effect of the use of the natural environment". Famous landscape architect Stuart think: "Any coordination with the ecosystem process mutually, make its damage to the environment to minimize the impact of design form is called ecological design. This coordination means respect diversity design, reduce the deprivation of resources, maintain the nutrition and water circulation, to maintain plant habitat and the quality of the habitat, to help to improve the living environment and the ecosystem health".

Design theory and method of the traditional emphasis on people-centered, from meet the needs of people and solving problems as the starting point, and ignore the effects on the surrounding 
environment design and its compatibility with the environment, the ecology theory is introduced into the design of ecological design, emphasizing multi-objective, total economy.

\section{The principle of landscape ecological design}

In the information society as the background landscape ecological design, is to the whole human ecological landscape elements of the system and their structure and function as the research object, through the scientific design and arrangement, eventually make landscape system structure and function to achieve the overall optimization. Landscape ecological design is usually need to consider the following principles, from the perspective of the overall, coordinator of relations:

Priority principle: (1)The natural protection of the natural environment, maintain the natural process is the precondition of using nature and remake nature. In the urban planning and construction, city give attaches great importance to the natural environment and, at the very least respect. A regional natural environment is the most basic embodiment of local characteristics, a city itself is a huge living natural ecology as a function of urban life the most basic and the most powerful guarantee.

(2)The overall design principle: landscape ecological design is the design of the overall human ecological system to conduct a comprehensive, design goal is the overall optimization and sustainable development. City is a huge complex life system, to ensure the city each component to achieve the optimal configuration must be the development direction of urban society and economy, the comprehensive study of city land function layout and public infrastructure.

(3)Comprehensive design principle: the complexity and diversity of landscape elements determines the implementation ideal landscape ecological design of multiple disciplines, in order to ensure the harmony and stability of the whole ecosystem. Aim to achieve sustainable development and build a harmonious, diversity, with distinctive characteristics of physical environment space, you must have a natural science, social science and research of urban development and the participation of all kinds of professional talents and social departments and collaboration.

\section{The concept of ecological planning and the landscape design thinking}

\section{(1) To promote the combination of landscape visual design and ecological design}

After years of landscape design practice has proved that when the landscape for best visual effects, and does not produce the desired ecological benefits. For example, to build a bright autumn landscape, the designer will commonly use to show the autumn maple community strikingly attractive, but analysis from the Angle of ecology, is not nearly as simplifies the ecological value of species diversity of tree species composition of plant community ecology. Some landscape design to change the nature, specially the curved river instead of the straight state, the Banks of the river use concrete hardening, serious damage to the ecological system, the author thinks that ecological design should be based on the law of nature, follow the natural law to realize the balance of the landscape design is reasonable.

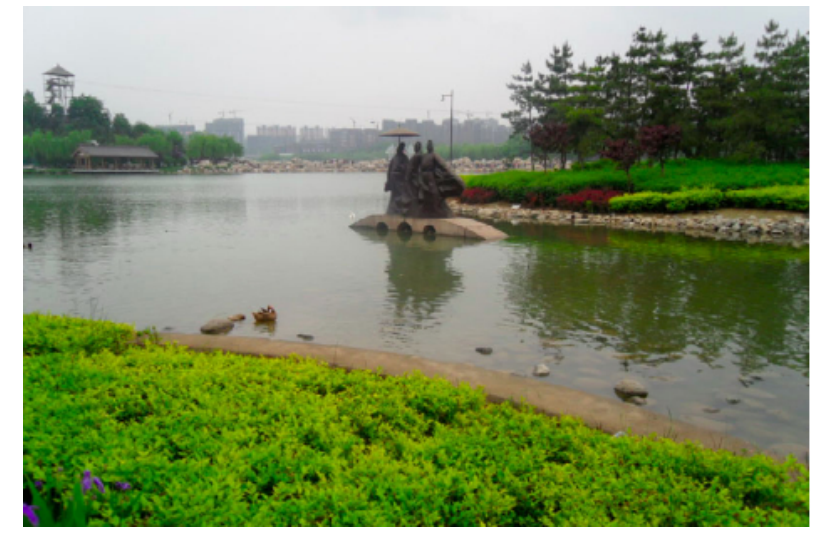

Figure 1 Park lake plant communities

(2)To be based on regional natural environment and climate characteristics 
Landscape is the organic combination of humanities landscape and the natural landscape, in the landscape ecological design must be based on the local geological and climate conditions. Climate conditions for regional biological conditions, water has an important influence, such as the design of landscape style have direct contact and climate characteristics, in the process of landscape ecological design should grasp the local meteorological comprehensive factors, scientific and reasonable analysis and design. Designers, for example, in a preliminary design according to the local climate conditions, change rule, and the characteristics of the temperature change to balanced collocation planting of different plant species, community make tree species of throttle monsoon period can shade in the summer, in winter climate does not influence the lighting effect; Also can according to rainfall, climate, temperature and humidity climate change reasonable choice of flowering of different plant trees and shrubs, make the landscape to show its seasonal changes, the best ornamental value.

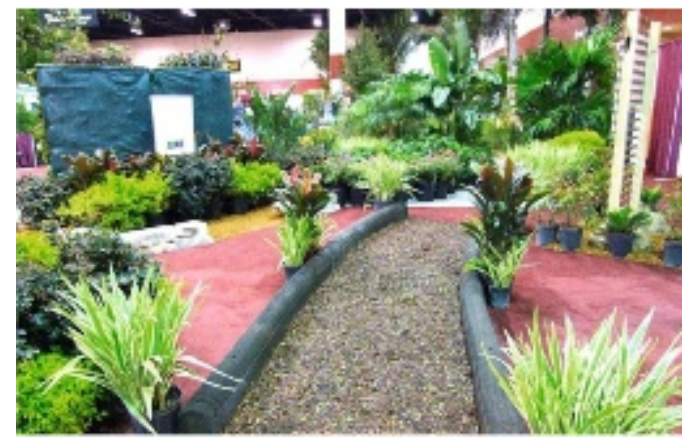

Figure 2 Florida landscape

In addition, the landscape ecological design should fully consider the local elements such as landform and physiognomy, every city has a fixed terrain and landform characteristics and unique plant species ecological system, and has the characteristic of history. In design of landscape ecology, therefore, should as far as possible not to undermine the original local topography, natural conditions and using area and building facilities to construct a new feeling of landscape, both retained the original historical and cultural sites, and satisfy the people's aesthetic, entertainment, activity basic needs. For the original topography, vegetation and water system for effective protection and utilization, try to keep the original topography, geomorphology and natural amorous feelings is the premise and foundation of landscape ecological design

(3) To ensure that the rich diversity of plant community ecology system

Biodiversity is for studying the biological and ecological system in recent years the focus of the content, mainly refers to the survival of biological species and ecological synthesis and ecosystem diversity and variability. Biodiversity, in general, including genetic diversity, species diversity, ecosystem diversity and the basic content of several parties. Genetic diversity refers to different biological species have genetic genes and genetic information, both in different population genetic variation, including the genetic differences within the same species, a variety of biological origin and complex natural environment is the important reason for the formation of genetic diversity.

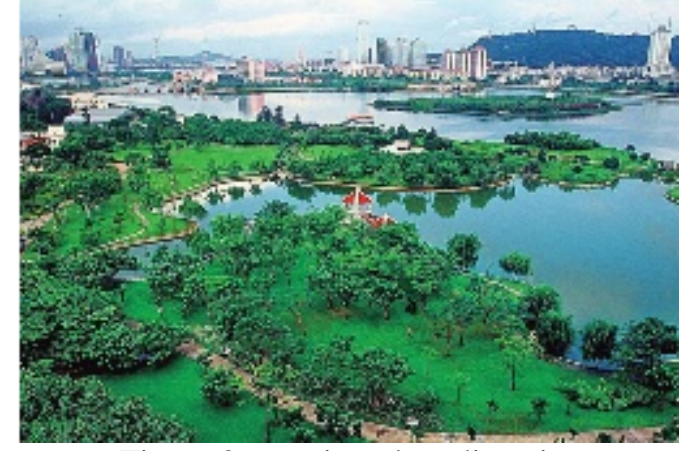

Figure 3 greening plant diversity

Species diversity refers to different kinds of types of biological species, and to highlight the variability of biological species, species diversity is the evolution of species occur gradually time, space, define and adaptability to the natural environment, is the most important product of 
evolutionary development. Mainly refers to the plant, animal, microbial ecosystem diversity of different species of ethnic communities the floorboard of the system and its ecological environment, species have been designated as the biological basis of biodiversity research and development efforts.

(4)We should fully consider the relationship between different plant species

The study found that plants in the normal life activities, can cause the other plants have different degrees of change, and can change the living environment and the surrounding environment, especially a lot of poisonous plants species produce certain toxic substances, seriously affected the growth of other plants. Elm if, for example, with small trees and shrubs, elm becomes backward way of growth; According to the tree and acacia trees can produce a certain amount of volatile substances, seriously restrain the growth of the plants around, make its living environment become bare land, etc.

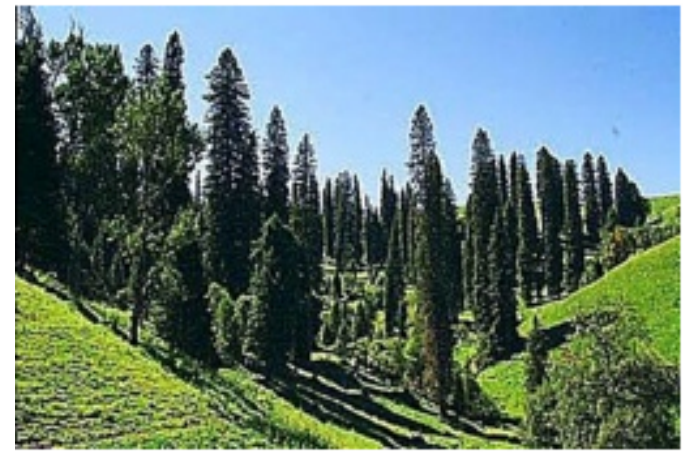

Figure 4 Ornamental plant communities

The study also found that some plant species can secrete a kind of useful material, can promote the growth of surrounding plants healthy and rapid. Acacia, for example, the root exudates can promote the rapid growth of poplar; The walnut and hawthorn can promote each other to grow. This must be familiar with the knowledge of biological theory, therefore, the designers at design time can effectively avoid the loss caused by mixing various plants, and can use a mutual promoting effect between different species, reasonable distribution of plant, in order to effectively create the best landscape effect.

\section{Summary}

With the development of era, the design requirements of landscape system should keep pace with The Times, and under the ecological design of greening system, insist on design should consider from multiple aspects, not only to consider ecological optimization of plant configuration, more appropriate to consider the ecological optimization of engineering measures, etc. Later in this area can be make more into further research to perfect.

\section{Acknowlege}

Foundation item: Jilin Agricultural University Youth Fund Project“Research on the Plant screening and Ecological Restoration in Changchun Municipal Landfill sites” (NO. 201319)

\section{References}

[1] Jim C Y,Liu H T.Species diversity of three major urban forest types in Guangzhou city, China. Porest Ecology and Management. 2008

[2] Chen ZZ,Wang SP.Typical grassland ecosystem of China. 2010

[3] Wang Dingwei.An inexact approach for linear programming problems with fuzzy objective and resources. Fuzzy Sets and Systems. 2009

[4] Godefroid S.Temporal analysis of the Brussels flora as indicator for changing environment quality. Landscape and Urban Planning. 2010 